DOI: 10.2478/rjes-2014-0023

\title{
IDENTIFICATION THROUGH TECHNOLOGY IN CONTEMPORARY CRIME NARRATIVES
}

\author{
FERENC KOCSIS
}

University of Szeged

\begin{abstract}
I propose a somewhat new approach to examine the characteristic epistemological concerns that can be witnessed in Detective fiction. An approach that takes into account a constituent of the said model and was not dealt with in depth previously: the inevitable technological mediatedness between the Subjects taking part in the interpretative process that defines the subject.

Keywords: Contemporary Epistemology, Detective Fiction, Subject Theory, Surveillance Technology
\end{abstract}

\section{Introduction}

A significant change took place around the turn of the new millennium regarding our understanding of acquiring knowledge. This change can be witnessed in the trends presented by contemporary Detective Narratives. An obvious influx of products of popular culture such as television series focusing on the phenomenon of detection implies that we have reached the next stage of a tradition that has worked as a model of our understanding of epistemological concerns for centuries now.

The aim of this paper is to provide supporting arguments for this shift and to propose an approach that can be used to examine these most recent developments of the Detective Fiction genre, such as the focus on technological mediatedness, the importance of infrastructure and providing a multifocal, comprehensive picture of the processes of detection and crime. This contemporary model can no longer be examined using the theoretical tools of the last paradigm - postmodern detective fiction - this is why I am confident that a further step is necessary in the tradition of academic examination of the genre. In the following pages I will present the new set of requirements regarding both the object of examination and methodology, and their supporting arguments, after addressing the historical, theoretical background of each above-mentioned development that differentiates Current Crime Narratives from Detective Fiction.

First, I will deal with the tradition of the classic tertiary categorization of Detective Fiction, with the hopes of providing an alternative, new constituent that is more suited to examine today's narratives focusing on crime and detection. The next step is to argue that, in order to be able to deal with the phenomenon at hand that is deeply rooted in praxis, it is necessary to include the findings, dominant trends of criminology, just as it is similarly vital to take an interdisciplinary approach to examination. After providing a possible new step in the tradition of Detective Narratives and proposing a somewhat novel theoretical approach of examination, I will focus on the inevitability of technological mediatedness. It is important to 
address how strongly this phenomenon is intertwined with both the notion of technological devices as extensions of the human body and law enforcement strategies when dealing with organized crime, financial crimes and the trafficking of illegal substances.

Emphasizing the advantages of examining the drug trade as opposed to the classical topos of murder, highlighting the temporal, structural, technological and linguistic aspects that make this subset more fertile is the next vital step. In the last section I will propose an object of examination that lives up to the system of standards that are discussed in this paper.

\section{The Next Step in the Tradition of Detective Fiction}

I am confident that in order to be able to examine the contemporary epistemological discourse as it is presented by today's Detective Narratives we have to rethink our approach towards these texts, works of art. Even though the classical approach that relied heavily on the content and historical context of these works proved to be more than useful during the past century, it is my opinion that the last stage of academic interpretation within this now classical system of division is outdated. This categorization of texts distinguishes three models that can be witnessed in terms of dynamics in these types of narratives referred to as the British model, the Hardboiled model and the Anti-Detective or Meta-Detective model. The emphasis in all of these models rests almost solely on the mystery, the case and the method the detective applies in order to find the perpetrator. The focus remained the same throughout decades even though the methods utilized went through serious changes.

It is a widely acknowledged fact that Detective Fiction, due to its strict and stable structure, could always be looked at as a direct reflection of the epistemological concerns and standpoints of the respective historical era in which it was produced. The parallel between the positivistic expectations of the Enlightenment Project and the solely intellectual, hermeneutic and physically detached methods of protagonists like Sherlock Holmes (Sir Arthur Conan Doyle's (2011) The Study in Scarlet, etc.) and Hercule Poirot (Agatha Christie's (1934) Murder on the Orient Express, etc.) is obvious, just as the shift from this approach to a more cynic and therefore hands-on mode of detection exemplified by equally iconic figures such as Sam Spade (Dashiell Hammet's (2002) The Maltese Falcon, etc.) or Phillip Marlowe (Raymond Chandler's (1970) The Big Sleep, etc.). It is argued by theoreticians such as Scaggs that the reason for this transition is rooted in the general disillusionment brought on by the Great War, an event that shattered humanity's high hopes of perpetual peace and understanding through relentless dedication to scientific improvement and moral evolution. The heroes of Hardboiled Detective Fiction are no longer part of the elite, the case itself ceases to be a simple intellectual exercise and finding out the truth does not necessarily restore the status quo. The distinction between detective and perpetrator starts to weaken; the protagonist does not have the luxury of keeping his distance from the underbelly of society. He has to go under and when he reemerges time after time he brings back more and more of that undesired dirt. He himself ends up becoming a stranger both to the elite, which he is supposed to protect, and to the criminal elements, which he is supposed to be fighting. Stuck in this liminal position, the only thing he can count on is himself but no one is inerrable. This is a clear-cut example of how humanity lost a great amount of hope in itself, due to the violent and previously unthinkable events of the beginning of the $20^{\text {th }}$ century.

The next significant shift took place after the Postmodern Turn. This event was brought on by the introduction of new and, up to this day, highly debated ideas into dominant Western Thought. Rooted in the works of radical thinkers like Derrida, Barthes and Lyotard among others, postmodernism as a school of thought problematizes the potentiality of the Enlightenment Project. Lyotard (2004:8) questions the possibility of acquiring objective and impartial knowledge and instead proposes that knowledge itself should be understood as a 
narrative that is the product of multiple, simultaneous discourses. The dynamic of discourse implies that knowledge can be generated through dissent, questioning the dominant views; in other words, knowledge should not be fixed. On the contrary, a certain amount of openness has to be maintained. This set of ideas, along with Deconstruction, Post-Structuralism and other inherently postmodern approaches, led to considerable conflicts within the academic community, for they openly defy the basic assumptions on which Western Thought was built. These ideas represent a sort of disillusionment similar in degree to the one that took place after the Great War, but this time it is not morality that is questioned, but the possibility to acquire incontrovertible knowledge in any field, be it the social or natural sciences.

It is a widely accepted notion that this shift in the general climate of everyday thinking led to the conception of the Anti- or Meta-Detective Fiction. Thomas Pynchon's The Crying of Lot 49 (1966) and Paul Auster's New York Trilogy (1987) are two trademark works that demonstrate the dominant underlying issues that characterize this subgenre of Detective Fiction. Using the strict structure of the genre, these authors could address newly raised questions regarding narratology and the idea of gaining knowledge, taking developments of the Postmodern Turn into consideration. These works can be understood as stylistic and narratological experiments rather than conventional stories. In each case the protagonist is doomed to fail due to the circumstances that are presented by the authors. The stories defy the basic rules of storytelling, the correct order or even presence of a beginning, a middle and an end, or the governing rules of causality, etc. Contingency, fragmented elements, the complete and obvious absence of conventionally mandatory elements of narratives define these works, serving as testaments to the unfixed nature of knowledge and structure in general.

If we accept the classical tertiary classification of Detective Fiction, the Anti- or Metasubgenre is the latest development in the long line of models mirroring our standpoint regarding knowledge in general. The problem with this standpoint is that, in a way, it entails the acceptance of inevitable failure.

We can witness basic notions - such as the parallel between the methods of detection and our understanding of knowledge - that remained the same throughout the centuries, carried on by the next historical model. Other notions went through a transformation in order to be applicable in the changing intellectual climate, questioning the goals and later the very possibility of detection. It is my opinion that it is time to recognize that there is an undeniable shift taking place once again, which requires the introduction of the next step in the tradition of Detective Narratives.

If we take a look at the present dominant trends in contemporary Detective Narratives, it is easy to see that recent works from the genre either go back to the British Model or the Hardboiled Model in a nostalgic attempt to revive these subgenres, or they mix the characteristic elements of these two models to create an amalgam. Instead of reaching back to these past models, I would like to introduce two subgenres that are not included in the classical division even though their first appearance predates Anti-Detective Fiction. These subgenres, the Police Procedural and the Crime Thriller are dealt with in detail in the textbook Crime Fiction the New Critical Idiom by John Scaggs (2005).

Police Procedurals such as Hillary Waugh's Last Seen Wearing (1952) and Ed McBain’s 87th Precinct novels (1950’s 1960’s such novels as Big Bad City, etc.) emphasize the importance of the institutional nature of the police. The lone detective's place is taken by an institution with significant resources such as manpower, finance, access to high level technology. Internal dynamics, structure, like the chain of command, or the notion of the partner, and complex relationships with other institutional organizations for example federal law enforcement agencies, correctional facilities and the judicial apparatus. Certain similarities can be pointed out with the British Model for the cases are no longer unsolvable, but in these narratives intellectual superiority is replaced by team effort and the use of 
technology. Even though this subgenre breaks from the total hopelessness of the AntiDetective Fiction, it is still very far from the positivistic approach of the Enlightenment due to "its commitment to social, structural, and thematic realism" (Scaggs 2005:94). Still, this is a noteworthy step forward in my opinion for once again there is a definite chance of success.

Crime Thriller focuses on the other side of the subject matter: the side of the perpetrator. Just think about Mario Puzo's The Godfather (1969) or Thomas Harris' Red Dragon (2009), The Silence of the Lambs (2002) or Hannibal (2000). The most important characteristic of this subgenre is its focus on the personality of the criminal, "the motivation for crime, and its after-effects” (Scaggs 2005:4); a factor that has been entirely left out or underemphasized at best in other subgenres.

What I want to propose is a model that takes these findings one step further and combines Police Procedurals and Crime Thrillers in order to create a more comprehensive model of crime and detection: Current Crime Narratives. This way we could examine the phenomenon of committing a crime, and the investigation that follows as it should be: as a set of multiple opposing interpretative processes instead of the classical approach that only takes one interpretative process into account. This way the model would no longer be prone to be oversimplified, or to be exclusive and thus not open enough to examine this complex social and theoretical phenomenon in depth.

Another important aspect of examining a complex phenomenon like the one at hand is to include theories, approaches from fields of science that deal with practice. This is especially important in the case of Detective Narratives, for both crime and the methods of detection are deeply rooted in praxis. To fulfill this expectation, I intend to incorporate the textbooks published as part of the Cambridge Studies in Criminology series (Blumstein and Farrington 1996-2011). These books will prove to be vital because they are based on actual case studies and give comprehensive accounts of different areas of crime and police work. The financial background of police forces, the most recent trends in criminology, the topos of murder, law enforcement and gangs, retaliation in the criminal underworld and white collar crime just to name a few. I am confident that these books can provide the practical side of the arguments that will have to be dealt with during the course of the examination. Besides, I think it would be faulty to exclude the findings of a field of science whose sole focus is the object of my examination. Postmodernism has a significant place along other approaches in criminology also; therefore, incorporating the methods and patterns found in criminology into an examination that primarily rests on literary theory is not just possible but desirable.

\section{Technological Mediatedness}

Taking the above-mentioned multiple-sided analytical approach leaves us with the other significant aspect of contemporary Detective Fiction that I feel is underrepresented: the inherent technological mediatedness of the present era. It is self-evident that everyday life today is more saturated in terms of technology than ever before. The abundance and ease of access to sophisticated machinery that would have been unimaginable just a few years ago is blatantly clear. In first world societies it is fairly safe to assume that any citizen above the poverty line has some means of recording, storing and sharing audio and video material at any given moment. Smartphones, digital cameras, and the internet are definitive constituents in our lives. Social networks provide a platform to share and gather all kinds of information on others without much effort, or specific skills. This development in personal life is still dwarfed by the extent of surveillance that is utilized by government and private agencies. In the post 9/11 US and UK, CCTV cameras became as common as phone booths or traffic lights. According to a 2007 article in the Daily Mail there were around 4.2 million CCTV cameras working in the UK alone, one for every 14 citizen and this number keeps growing 
steadily ("UK has $1 \%$ of world's population but $20 \%$ of its CCTV cameras"). This obsession with constant surveillance as a way to protect the citizens is justified by the notion of the War on Terror.

But the roots of surveillance go back much further. To investigate the historical background of this topic I will rely on the textbook Understanding Surveillance Technologies - Spy Devices, History and Applications by J. K. Petersen. The first documented interception of a transmission, according to Petersen (2007:125), took place as early as 1858 and can be attributed to a man called Anson Stager. According to the accounts of the events, Stager was travelling by train in the USA when the train broke down due to engine malfunction. It would have taken too much time to walk or ride to the next town and order a replacement, but Stagger had some pressing business to attend to so he took matters into his own hands. Being familiar with the Morse code, he cut down the telegraph wire and sent a message requesting a new engine by tapping the bare end of the wire with a stick to transmit, and by putting the wire on his tongue to receive small electrical shocks that he could decode. This event is a graphic depiction of how technological devices can serve as prosthesis to the human body, providing access to a network of communication that can bypass temporal and spatial difficulties. In this way technology has made everyday life easier but it also holds its fair share of difficulties as well. Since their invention, communication technologies have served as an extension of the human body, expanding the number of ways in which we communicate, but this development has also opened up a whole new set of possibilities for abuse.

Besides the purely technological aspects, the other important historical and methodological root of surveillance can be traced back to criminology, and law enforcement tactics. The first unsanctioned wiretap by a law enforcement agency can be dated to 1916 (at the time, issues of regulation regarding such actions were not in place yet), when "a New York mayor authorized wiretapping of Catholic priests in a charity-fraud investigation, without demonstrating that there was sufficient cause to initiate the action" (Petersen 2007:131). It was only in 1967 after the trial of Katz vs. United States that probable cause was mandatory to tap public phones. By 1968 organized crime has spread to such an extent that, in order to gather reliable information, listening devices became a necessity after "a number of studies concluded that the impenetrability of criminal groups justified wiretapping and bugs in law enforcement" (Petersen 2007:143). In 1970 all telecommunication service providers had to start using hardware and software that was in accordance with the devices used by law enforcement for surveillance, making wiretaps and other forms of interception and monitoring faster and considerably easier (Petersen 2007:146).

Petersen (207:137-139) also finds it important to mention some of the most notable advantages of using bugs (listening devices), and intercepting communication as opposed to relying on informants or undercover officers. First of all, electronic devices are far more reliable than informants. The information they provide is objective. On the other hand, informants have shown tendencies to make up stories and hold back information in order to maintain their position within the law enforcement agency, or the criminal organization they are in connection with. Using bugs instead of undercover officers largely reduces the risk taken by said undercover officer, and it is also a solution to the ever present problem. In order to keep their cover, officers of the law often had to engage in criminal activities to gain the trust of their targets and these activities then jeopardized the success of the investigation.

In short, it would seem that electronic surveillance is a reliable method of gaining objective information regarding a case, but due to the complex set of regulations that have to be taken into consideration, and the inherent possibility of malfunction or simply the loss of information due to the physical circumstances (distortion, interference), the information gathered through this method is often incidental and/or fragmented. This presents a whole set 
of difficulties to the parties engaged in surveillance, but is also in accordance with the postmodern assumptions about the nature of information.

After presenting a list of requirements in terms of the content and approach of Current Crime Narratives, it is still necessary to designate a sub-set of criminal activity, and detection that serves these expectations the best. In my opinion, we have to replace the topos of murder - the most conventional focus of Detective Fiction - with the topos of trafficking of illegal substances for the following reasons: the drug trade implies a set of features that allow a deeper and more complex examination; this particular type of activity prevailingly takes place over a period of time, utilizing repeat offenders who work in a network, as opposed to a single perpetrator committing a single crime; the nature of this business requires regular back and forth communication between the members of the organization, elevating surveillance into a position of inevitable importance. Another noteworthy characteristic of the investigations regarding the sales of illegal substances is that money and product is in focus and not the body as in the case of classical murder investigations. This is important because money and crimes of financial nature transgress the boundaries of class, thus creating a bridge between blue collar and white collar crime. In the case of murder no such investigative opportunity is guaranteed. Besides, homicides are regular byproducts of the drug trade, just as many other forms of street crime. This radical change in the baseline of our moral and ethical expectations regarding society is, in my opinion, a clear-cut example why it is justified to talk about a next step in the tradition of Detective Narratives.

\section{An Ideal Object of Examination}

Now that this set of expectations based on the trends witnessed in current Detective Narratives is in place, the next step is to find an object on which these expectations can be examined in depth. To recap my previous arguments: the model has to include points of view from both sides of the law ideally simultaneously; both sides have to be represented in a comprehensive manner based on either actual events or dynamics that mimic actual events; otherwise, the stress on including criminology in the interpretative approach would be inconsequential.

The above-mentioned elements are easy to find in a subset of the last decade's popular TV series, specifically the ones that are focusing on the themes of crime and detection. The CSI (Zuiker 2000-) franchise clearly emphasizes the importance of utilizing technology as the sole viable tool of detection but does not include the point of view of the perpetrator. In the television show Dexter (Colleton 2006-) the audience is presented with a comprehensive picture regarding crime and police procedures, for the protagonist is a serial killer who is working for the Miami Dade County Police Department as a forensic analyst, but the importance of technology is underrepresented in the favor of hands-on investigation. The emphasis on team effort taking over the role of individual investigation is the central motif that can be found in most - if not all - current narratives focusing on crime.

My proposition is to examine the TV series titled The Wire (Simon 2002-2008) for it treats fully and simultaneously all the different requirements of Current Crime Narratives that I voiced earlier. It was written by a former homicide detective of the Baltimore Police Department with extensive background in surveillance cases, and a former crime reporter of the Baltimore Sun. Based on their firsthand experience, it provides a comprehensive multiplesided picture of the inner city drug trade, and the complex socio-economic and technological connotations that surround this phenomenon.

It is also important to briefly define my standpoint regarding the analysis of television series. Instead of relying on the earlier approaches popular within the field, I agree with the analytical position outlined in Kristin Thompson's (2003) book on the subject Storytelling in 
Film and Television. Thompson argues that television shows can be examined as standalone products in order to be able to focus on their narrative and aesthetic values instead of the aspect of reception. This former approach can be attributed to Raymond Williams who coined the term flow to describe the experience of watching television. The term flow is also used to describe "a sequence or set of alternative sequences of these and other similar events, which are then available in a single dimension and in a single operation" (Williams 2003:87). In his opinion, the truly postmodern characteristic of television is that the different programs follow one another creating a sort of weave that engulfs the viewer. The problem with this notion is that it supposes that viewers either cannot or will not differentiate between different programs, commercials or public announcements. While certainly being interesting and novel, this approach does not take into account the intelligence of the viewers, depicting them like automatons that consume any and all data without question or common sense. Still "the concept of flow" became so popular "that television theorists often seem unable to conceive of an approach that does not rely on this root metaphor" (Thompson 2003:8). John Fiske, another prominent thinker of the field still did not consider individual programs as organic units, but in his model "the viewer 'enters the text' in an imaginative and creative way" (Fiske 1987:102). The audience has the capacity to change channels, thus providing them with the possibility to assert some degree of control over the flow of information. Still, Fiske was mainly interested in reception, and not the material broadcasted. What Thompson points out is that if we assume that television programs are organic units, then it is fairly easy to support this argument, for the basic narrative structure of these programs is analogous with the structure of any narrative that follows the Aristotelian traditions.

Accepting this analytical position opens up the possibility to examine television programs that fall into the category of contemporary detective fiction in terms of narratology, underlying logic, and their relationship with the phenomena they try to depict. In this way, we treat these products as any other textual narrative because the focus is no longer on something that is outside of the narrative worlds - such as reception, or their respective place in the TV Guide - but on these texts and their connotations.

\section{Conclusions}

The subset of popular TV series of the last decade focusing on the theme of crime and detection provide an excellent example of how shifts in our general understanding of abstract or very concrete concepts bleed into arts, popular culture. In order to be able to examine this new standpoint we need to assume a new theoretical, academic approach.

As I pointed out previously, Current Crime Narratives include elements which make the use of the tools of examination of the Anti or Meta-Detective Fiction model - the last classical step in the tradition - insufficient. What I propose is not a radical break from this tradition, rather a next step in accordance with it, a step that fulfills the requirements raised by these narratives.

The examinational method I propose is based on the notion of comprehensive depiction of the phenomenon of crime, multidisciplinary approach, and a strong emphasis on the inevitability of technological mediatedness. It is my firm opinion that Current Crime Narratives represent a significant change in the tradition of Detective Fiction and our understanding of acquiring knowledge in general. This shift is characterized by radical displacements - from focusing solely on the interpreter, to focusing on the network that connects all the participants of this complex dialogical process - and by the possibility to deconstruct the central position of the topos of murder and to address it only as the byproduct of a much more complex network of crime. 


\section{References}

Auster, Paul. 1987. The New York Trilogy. London: Faber and Faber.

Blumstein, Alfred and Farrington, David (Eds.). 1996-2011. Cambridge Studies in Criminology. New York: Cambridge University Press.

Chandler, Raymond. 1970. The Big Sleep. London: Penguin Books.

Christie, Agatha. 1934. Murder on the Orient Express. New York: HarperCollins Publishers.

Colleton, Sara (Executive producer). (2006-present) Dexter [Television series]. USA: Showtime.

Doyle, Arthur Conan, Sir. 2011. The Study in Scarlet. New York: Penguin Books.

Fiske, John. 1987. Television Culture $2^{\text {nd }}$ edition. New York: Routledge.

Hammett, Dashiell. 2002. The Maltese Falcon. London: Orion Books.

Harris, Thomas. 2009 (1981). Red Dragon. London: Arrow Books, Random House Group Limited.

Harris, Thomas. 2002 (1989). The Silence of the Lambs. London: Arrow Books, Random House Group Limited.

Harris, Thomas. 2000 (1999). Hannibal. London: Arrow Books, Random House Group Limited.

Lyotard, Jean-François. 2004. The Postmodern Condition: a report on knowledge. Manchester: Manchester University Press.

McBain, Ed. 1971. The Big Bad City. Seattle: Thomas and Mercer.

Petersen, J. K. 2007. Understanding Surveillance Technologies - Spy Devices, Privacy, History and Applications. Boca Raton: Auerbach Publications.

Puzo, Mario. 2009. The Godfather. London: Arrow Books, The Random House Group Limited.

Pynchon, Thomas. 2000. The Crying of Lot 49. London: Vintage Books.

Simon, David (Creator). (2002-2008). The Wire [Television series]. USA: HBO.

Scaggs, John. 2005. Crime Fiction - The New Critical Idiom. New York: Routledge.

Thompson, Kristin. 2003. Storytelling in Film and Television. Cambridge: Harvard University Press.

Waugh, Hillary. 1976. Last Seen Wearing. London: Macmillan.

Williams, Raymond. 2003. Television and Cultural Form. London: Routledge.

Zuiker, Anthony E (Creator). (2000-present). CSI: Crime scene investigation [Television series]. USA: CBS.

***. 2007. "UK has $1 \%$ of world's population but $20 \%$ of its CCTV cameras." Daily Mail. Available: http://www.dailymail.co.uk/news/article-444819/UK-1-worlds-population-20-CCTV-cameras.html [Accessed 2014, 18 February].

\section{Notes on the author}

Ferenc KOCSIS received his Master's Degree from the University of Szeged, Faculty of Arts in English Literature and Culture. He finished the British and American Literatures and Cultures post-graduate PhD program at the University of Szeged in 2013. His research areas are semiotics, postsemiotic subject theory, poststructuralist literary theory and narratological examination of postmodern literature and popular culture with a special focus on television series. He is currently working on his $\mathrm{PhD}$ thesis focusing on the comparative aspects of practical and theoretical criminology and the epistemological processes that can be witnessed in contemporary crime narratives. 